\title{
La percepción de la otredad en cuatro narradores
}

Federico PATÁN

Universidad Nacional Autónoma de México

Desde un punto de vista muy simplificado, cabe describir toda narrativa como un proceso mediante el cual alguien dice algo de alguna persona. Si de esto partimos, la fórmula permite tantas aplicaciones que resulta casi inútil por vaga, aparte de que nadie conseguirá abarcar todas sus posibilidades. Pero esa vaguedad encierra un nicleo cierto: ese proceso de contar lo ocurrido con quien narra o con cualquier otro individuo. Cuando los hechos presentados al lector pertenecen al mundo de la aventura o de la acción, el narrador enfrenta una labor sencilla: informarnos, con el mejor ritmo posible, de las muchas proezas llevadas a cabo por el héroe. Mundo de opciones claras y perfectas, el de la novela de acción no da pie a titubeos: nadie tendrá problemas en diferenciar a los buenos de los malos. Se ha establecido un código de signos que nos entrega resuelta la identidad de los personajes. Allí están, en la limpia tranquilidad de los nichos que resguardan sus imágenes fijas.

La narrativa va adquiriendo complejidad según nos alejamos de esa literatura divertidísima pero superficial. Poco a poco nos adentramos en terrenos donde personajes, conductas y tramas procuran reproducir, con recursos narrativos de mucha mayor sutileza, los filos secretos de nuestro mundo. Ocurre de esta manera que, como lectores, nos vemos introducidos en ámbitos donde la aguja de marear que utilizamos - la cultura en la cual nacimos - se torna una ayuda frágil. Hay ocasiones en que la perplejidad es la única bahía de resguardo. Hemos entrado en lo apenas conocido o en lo plenamente ajeno.

La cultura, pues. Comencemos a examinar el problema desde el autor mismo. Lo sabemos prisionero de su cultura en aspectos que está lejos de imaginar; sabemos que escribe como escribe porque a esa cultura pertenece. De aquí las agudas y en ocasiones curiosas diferencias hallables cuando una trama cambia de país: la leyenda de El Judío Errante según perspectiva de Eugenio Sue (1804-1857) o de acuerdo con la interpreta- 
ción de Par Lagerkvist (1891-1974). En tanto que prisionero, de vez en cuando hace el intento de escapar a su condición, y la simple existencia de tal intento lo define como prisionero. De esta manera, creamos narrativa dentro de los ordenamientos restrictivos de nuestra cultura porque somos nuestra cultura. $O$ en palabras de Tzvetan Todorov, "cada una de ellas es un modelo del mundo", ${ }^{1}$ y medimos el universo de acuerdo con ese patrón. Desde luego, hay mentes capaces de cambiarlo a partir de conocerlo en profundidad. En el campo de la literatura ésa es, precisamente, la tarea de los creadores excepcionales: modificar a partir de 10 heredado.

En la novela de aventuras es permisible un cierto grado de xenofobia. Surge de los requisitos del género. Es parte de aquel código de signos que facilita al lector su tarea: en Sax Rohmer (1886-1959) todo chino es traidor y su presencia fácil de interpretar como peligrosa para lo occidental. ¿Por qué lo extranjero? Porque es lo desconocido y lo desconocido vive amenazán donos mientras no lo convirtamos en dato asimilable. ¿No son los territorios vírgenes zonas imprescindibles para provocar la zozobra del héroe $y$, por tanto, la ansiedad del lector mediante el suspenso? Pero ¿y qué de las literaturas cuya naturaleza es más sutil? En ellas ¿hasta dónde es permisible la imagen distorsionada de una cultura ajena? ¿Hay regla alguna en esta variedad de juego? Y excusas ¿las hay? Cada caso es una circunstancia en sí mismo. La distorsión puede darse por vía de una imagen de lo ajeno limpiada de impurezas, o caer en la denigración del universo encontrado. No existe acercamiento sin su dosis de modificación. No queda, pues, sino medir el grado y la naturaleza de ese acercamiento.

Prisionero de sus fronteras, en ocasiones el narrador trabaja sin darse clara cuenta de lo injusto que su texto resulta. En otras ocasiones, el ataque contra la cultura ajena parece premeditado. Arriba lo dijimos: pudiera ocurrir que la distorsión fuera efecto del amor. Allí tenemos a Katherine Anne Porter y México. Amaba ella este país pero, de acuerdo con Thomas F. Walsh, "escape from reality became a major theme in Porter's fiction. Her own adventures in Mexico were a form of escape from depression". ${ }^{2} \mathrm{He}$ aquí una idea nada escasa en la literatura: alejarnos de la patria en busca de nuestro verdadero ser interno. Recuérdese el

\footnotetext{
${ }^{1}$ Tzvetan Todorov, Nosotros y los otros. Trad. de Marti Mur Ubasart. México, Siglo XXI, 1991 (Serie teoria), p. 86.

${ }^{2}$ Thomas S. WALSH, Katherine Anne Porter and Mexico: The Illusion of Eden. Austin, Universidad de Texas, 1992, p. 44.
} 
párrafo final de An American Dream (1964) o los desplazamientos de D. H.Lawrence por el mundo.

Sea cual fuere la instancia motivadora en la visión de lo ajeno tenida por un autor - curiosidad, amor, odio, afán de aventura-, todos los que escriben acerca de una cultura extranjera comparten la misma obligación: enfrentarse a una otredad. Hablando de la cual, el diccionario más completo de la serie Webster's dice: "the quality of being not the same", modo un tanto primitivo pero a la vez útil de exponer el asunto, pues subraya el aspecto principal: ser algo distinto. En español se utiliza el término 'alteridad' y sólo en los diccionarios de filosofia aparece ocasionalmente el de 'otredad', condición descrita como el ser otro, el colocarse o constituirse como otro. $Y$ ya tenemos presente la idea de variedad.

Así pues, alteridad es el concepto clave en esa naturaleza ajena enfrentada a la nuestra. Concepto que habita en la literatura desde tiempos inmemoriales, bien que haya sido con otros nombres. No hace falta sino que un personaje inicie viaje para que, tarde o temprano, se vea forzado a reconocer otra idiosincracia, lo cual significa decidirse por alguna actitud. Allí está Room With a View (1908), de E. M. Forster (1879-1970), donde hallaremos la expresión cortés - si bien aceradadel problema; Walter van Tilburg Clark (1909) opta por el otro ángulo, la violencia, en The $O x-B o w$ Incident (1940). Poco a poco la crítica entendió la importancia de este aspecto de la narrativa, y lo fue explorando con atención creciente. De pronto, no sólo fue deseable sino obligatorio determinar quién narraba, desde cuál punto de vista lo hacía, y cuáles eran las consecuencias de tener un determinado narrador y un determinado punto de vista.

De esta manera, veamos quién narra, y desde cuál punto de vista, en cuatro libros de cuatro autores diferentes. Deduzcamos si esto tiene alguna influencia en nuestra lectura de los textos. Como "alteridad" es el término central a nuestra indagación, hemos elegido obras donde la presencia de un elemento extranjero crea un problema de acercamiento. En orden cronológico, se trata de The Power and the Glory (1940), de Graham Greene (1904-1991), donde una conciencia inglesa echa un vistazo a una de las realidades mexicanas; Cuentos mexicanos (con pilón) (1959), de Max Aub (1903-1972), donde un escritor hispano recrea un mundo mexicano; Las posibilidades del odio (1978), de María Luisa Puga (1944), donde una mexicana se compromete con cierta situación africana; y finalmente Las hojas muertas (1987), de Bárbara Jacobs (1947), donde un extranjero decide radicarse en México. 
Cada una de estas novelas significa un modo diferente de abordar el problema que nos ocupa. Véase The Power and the Glory. Su autor, Graham Greene, fue un viajero infatigable, en parte a causa de sus tareas periodísticas, en mucho porque a ello lo conducía su propia naturaleza inquieta. Un examen de los libros que escribió permite relacionarlos de inmediato con los países visitados. Lo curioso es que en ninguno de estos sitios quedó por largo tiempo. Cuestión de meses, en los casos extremos. Y sin embargo, esos lapsos parecen haberle bastado para reunir la información que le era necesaria. Necesaria, al menos, para los propósitos del texto. Asi con México. Vino en 1938, comisionado para escribir una serie de artículos sobre la situación religiosa entonces prevaleciente aquí. El punto de vista directamente personal aparece en Lawless Roads (1939); la interpretación narrativa pertenece a la novela.

Comencemos por una cita tomada de fuentes mexicanas. En 1924 Plutarco Elías Calles sube a la Presidencia. La Revolución mexicana había terminado pocos años atrás, pero seguía muy presente en las inquietudes de todo el mundo. Por tanto, "en los años que corrían, las nuevas realidades de la sociedad y de la economia produjeron, en mayor o en menor grado, pero necesariamente, una agilización de las conciencias y una clara apetencia de mejoramiento espiritual. Por eso cuando la Iglesia, sin entender los cambios operados en el pais, intentó cerrar el paso a la libertad de conciencia y a unas posibilidades más amplias para la educación, hubo de quedarse casi sola". ${ }^{3}$

Tal es la imagen propuesta por un libro de historia importante. Es, de alguna manera, la posición oficial. Ahora, vayamos a una reseña escrita por Greene en 1940. La obra comentada tenía como título Mexico: A New Spain with Old Friends, siendo su autor un profesor de Cambridge: J. B. Trend. Graham Greene se muestra decididamente contrario a la interpretación que de México hace el señor Trend y la califica de turística, dándole al término un significado muy despreciativo. No es difícil señalar el motivo de la oposición mayor: que el profesor inglés se haya preocupado escasamente de la situación religiosa del país. Citemos de la resención estas palabras: "I assure him that in the very year he was in Mexico he had only to travel a little farther afield to discover States where the churches where either destroyed or locked, where priests were forbidden to say Mass [...]"4 ¿Miente Greene? Desde luego que no.

\footnotetext{
${ }^{3}$ Daniel Coslo Villegas et al., Historia minima de México. México, El Colegio de México, 1974, p. 148.

${ }^{4}$ Graham Greene, Collected Essays. Harmondsworth, Penguin Books, 1970, p. 254.
} 
Sucede tan sólo que ambos puntos de vista dicen su verdad: fue necesario recortarle los poderes a la Iglesia y, al mismo tiempo, hubo casos innegables de crueldad hacia los creyentes. Sucede alli donde las cuestiones políticas gravitan de cerca sobre la vida de los ciudadanos. Al parecer, es un hecho a la vez triste e inevitable que las decisiones abstractas tomadas en la cúpula gubernamental, se degradan cuando los funcionarios menores las transforman en aplicaciones concretas.

Greene se decidió por la palabra "turista". Con ella definía el acercamiento de Trend a la realidad mexicana de 1938 . Significa esto que no veía sus propios desplazamientos por el país como una empresa turística. Quizás se colocaba en el apartado de "viajero"; es decir, quien busca algo más que la glosa superficial de los puntos visitables en cualquier nación. ¿No lo acompañaba, acaso, su agudo mirar de periodista? Conviene entonces ir a The Power and the Glory y preguntarnos ¿quién está narrando los hechos? Aunque novelista poderoso, Greene jamás intentó superar los recursos literarios recibidos del pasado. En parte heredero de Robert Louis Stevenson (1850-1894), en este caso opta por un narrador extradiegético, que de vez en cuando se introduce en la mente de los personajes.

Los sucesos ocurren en un lugar indeterminado de México, aunque casi seguramente Tabasco y Veracruz, estados donde se dio la problemática que sustenta a la novela. Además, el paisaje de esas regiones coincide con las descripciones hechas por el autor. Atendamos las líneas iniciales del texto: "Mr. Tench went out to look for his ether cylinder, into the blazing Mexican sun and the bleaching dust. A few vultures looked down from the roof with shabby indifference: he wasn't carrion yet". 5 Una apertura muy maliciosa, que de inmediato capta la atención del lector. Después de todo, Greene es un buen artesano de la novela y, por otro lado, The Power and the Glory cuenta entre sus mejores obras y tal vez sea la mejor.

Sucede que, en cuatro líneas, tenemos la introducción de un personaje importante, la creación física de una atmósfera, el señalamiento de una decadencia y, sutilmente, la mención de un tema que correrá por toda la obra: el acoso de la muerte. Pero nos interesa la voz narradora. Entonces, conviene subrayar ciertos detalles. Por ejemplo, la palabra "vultures" (buitres). No los tenemos en México. Nos hemos conformado con los "zopilotes", una versión menos elegante de los comedores de carroña. Los zopilotes corresponderían mejor a la realidad mexicana, pero tal vez

${ }^{5}$ G. GREenE, The Power and the Glory. Harmondsworth, Penguin Books, 1962, p. 7. 
nada signifiquen para un lector europeo sin la correspondiente nota a pie de página. Por tanto Greene, y le dam os la razón, elige el equivalente más próximo. No está de más señalar la presencia de buitres en The Heart of the Matter (1948), novela situada en África. Interesante, la coincidencia.

Es muy sencillo explicar lo que buscamos definir con este apunte: Greene escribe desde un punto de vista inglés para un punto de vista inglés. De un modo sutil, ofrece un discurso crítico donde el lector europeo confirmará la imagen que su cultura le ha creado de esos lugares lejanos y exóticos. En otras palabras, no deja de percibirse el oculto sentido de superioridad compartido por Greene y sus conciudadanos. A no ser que nuestra propia cultura nos haya sensibilizado la piel en exceso, al grado de hacernos ver estas intenciones donde no las hay. $Y$ sin embargo, los personajes extranjeros coinciden en tener una visión bastante pobre del lugar en que viven. Sírvanos de ejemplo el señor Tench, quien piensa: "He had said the boat would not go before morning, but you could never trust these people not to keep to time-table [...]"6 Pero atendamos otra cita: "From eight-thirty in the morning until eleven he dealt with a case of petty larceny: there were six witnesses to examine, and he didn't believe a word that any of them said. In European cases there are words one believes and words one distrusts [...]"7 No es la misma novela, aunque sí el mismo autor y la misma aproximación a una cultura ajena. En la cita última, África y The Heart of the Matter.

$Y$ henos aquí en una situación curiosa: para una percepción mexicana, el México de The Power and the Glory tiene un ligero sabor africano. Intuimos en el discurso la presencia de un narrador sin un sentido real de nuestro yo interno. Desde luego, ambas citas pertenecen a personajes de las respectivas novelas, y el narrador se limita a transmitirnos lo que aquéllos piensan, apoyándose en lo que Dorrit Cohn describe como monólogo narrado.

Ahora bien, en ocasiones la voz narradora habla por sí misma y, curiosamente, no hay diferencias. Por ejemplo, observa a un niño mexicano y comenta: "He wore a big hat and had stupid brown eyes". ${ }^{8}$ Se diría una descripción neutra, apegada a la realidad vista; pero cuando los ejemplos se van acumulando, sólo hay una conclusión posible: el narrador no siente simpatía ni por la gente ni por el país utilizados en la novela. Porque justo eso es lo que Greene hace: utilizarlos para trans-

6 Ibid., p. 18.

${ }^{7}$ G. GREENE, The Heart of the Matter. Harmondsworth, Penguin Books, 1962, p. 133.

${ }^{8}$ G. GREENE, The Power and the Glory, p. 16. 
mitir la preocupación que como autor tiene por ciertos temas fijos, presentes a lo largo de la obra que dejó escrita: el sentido de traición, la angustia de la soledad, la necesidad de darle un significado a la vida. $Y$ no hay duda de que los utiliza en una novela hecha con buen oficio, pero novela con una definitiva afirmación de la supremacia europea. Afirmación de ninguna manera inevitable, como veremos en nuestro siguiente escritor, Max Aub (1902-1972). Pero antes volvamos a la reseña de Greene, donde insiste en que Trend se equivocó porque, entre varias razones más, hizo amistad "with Spanish Republicans as strange to the country as himself". ${ }^{9}$ Caso indudable de ver la paja en el ojo ajeno. Aub era uno de esos republicanos, y su libro de cuentos es una refutación muy sólida de las apresuradas líneas de Greene. Nos parece que éste repetía, en lo personal, la postura de su gobierno respecto al gobierno legal de España, el republicano. De cualquier manera, Aub era un exiliado político. En términos de Todorov, "aquel que interpreta su vida en el extranjero como una experiencia de no pertenencia a su medio, la cual ama por esta misma razón". ${ }^{10}$ El exiliado sabe que va enraizando definitivamente en su nuevo país, y que el único modo de resolver los conflictos de desarraigo está en llegar a un acuerdo con esa realidad insólita llamada "la otra cultura". A la cual se acerca con un máximo de prudencia y de cautela, manteniéndose dentro de lo que viene a ser un gueto espiritual; o bien con la cual intenta mezclarse sin poner en peligro su yo interno; o a la cual se entrega del todo, sabedor de que ésta lo mira con diversos grados de ponderación.

Cuando Aub llega a México en 1942, después de tres años en campos de concentración franceses, es autor de un cierto número de títulos -cuento, ensayo, poesía, teatro-, pero el grueso de la obra está por cumplirse en el nuevo país. Su producción mexicana es de un volumen en verdad impresionante. Muy pronto, esos escritos incluían la nueva y desconocida realidad, vista con ojos sorprendidos por diferencias imprevistas: el paisaje, los estados de ánimo de la gente, las costumbres sociales y la lengua. La lengua, sí. Aunque las dos naciones tienen como idioma oficial el español, siglos de usos distintos han creado una brecha muy notable en vocabulario, sintaxis, ritmos de expresión.

Cuando Greene llega a México, lee al pais en inglés y en inglés escribe acerca de él. Aub se encuentra en la situación paradójica de sentirse fuera de su nueva realidad debido a los obstáculos creados por

${ }^{9}$ G. GReEnE, Collected Essays, p. 252.

${ }^{10}$ T. TOdOROV, op. cit., p. 392. 
el empleo del mismo idioma, el español. Al parecer, sólo un modo de acercamiento es posible inicialmente: aceptar lo que estaba sucediendo y obedecer los límites lingüísticos dentro de los cuales se nació. Pero claro, el tallado constante de la lengua mexicana sobre la peninsular dio a la escritura de los exiliados españoles un matiz nuevo. De esta manera, sin convertirse en mexicana, esa escritura ya no era del todo española. El contacto de dos otredades llegó a una especie de acuerdo en la creación de una tercera y anfibia alteridad.

Al escribir sobre la realidad mexicana Aub tenía a su disposición tres aproximaciones: narrar como español, mirando su nuevo universo con ojos de extranjero; intentar comprender desde fuera esa cultura en los términos por ella establecidos; vestirse de mexicano. El libro que vamos a comentar se desplaza por los tres caminos, cada uno de ellos aprovechado con un propósito específico.

El título mismo es ya una declaración: Cuentos mexicanos (con pilón). Difícilmente un escritor mexicano sentiría la necesidad de afirmar que se está refiriendo a una cierta realidad nacional. Aub, exiliado español, se permite un toque de ironía, un guiño de ojos, cuando dice: juguemos a ser mexicano. $Y$, desde luego, la palabra "pilón" pertenece del todo a México y con su presencia está ejerciendo una ironía adicional.

Los cuentos tienen lugar en México y, lo comentamos ya, siguen las tres sendas mencionadas. De esta manera, hay ejemplos de narrativa mexicana vista como narrativa mexicana. Para conseguirlo, Aub se apoya sobre todo en dos elementos: la psicología y el lenguaje. Hasta donde le es posible, se aparta del punto de vista español y procura describir los personajes como lo haría un mexicano. No busca la sutileza: opta por los rasgos de conducta más próximos al lugar común, o lugar común sin salvedades, y los ofrece como representativos de nuestro modo de ser. Así, y para aclarar mediante un ejemplo, describe la cultura campesina de México como propensa a la venganza; como proclive a guardar en silencio una ofensa, hasta llegado el momento oportuno de la susodicha venganza; como hecha de melancolías y reservas. Ya el cine mexicano de los cuarentas se inclinaba demasiado a temas parecidos 0 iguales. Es una vieja tradición cultural, muy necesitada de perspectivas nuevas. Ese mismo cine decía en imágenes que el charro era un hombre de violencias, dispuesto a ver en todo una provocación, listo a imponer con el revólver que su machismo era genuino y temible. Con un sentido del humor delicioso, Aub toma esos lugares comunes y los aprovecha para hacer burla de ellos. Porque, en un buen número de casos, esta literatura es irónica. En parte por eso, para dar pie a comentarios 
mordientes al autor le bastan los rasgos gruesos de una cierta realidad mexicana.

Así, Aub se disfraza de mexicano para criticar su nueva circunstancia. La máscara, ¿quién lo duda?, no es perfecta. El empleo mismo de lugares comunes traiciona un enfoque hecho desde fuera. El lenguaje pasa ocasionalmente a un registro español, revelándonos que el autor no es nacional al cien por ciento. Palabras como "oliváceos", "albéitar", "regol farse" o "rebozada" lo confirman. Pero son deslices menores en una imitación por lo general excelente de un habla mexicana campesina.

Por necesidades de equilibrio, Aub da voz a varios españoles. El cuento llamado "El caballito" es un ejemplo cabal de este ángulo de visión. Sin embargo, cierta cautela se impone. Es protagonista un sacerdote español que pasó algunos años en México. Incapaz de acomodarse a la realidad alli encontrada, vuelve a su país, España. Manda entonces una larga misiva al arzobispo de Guadalajara, explicándole por qué México resulta un lugar imposible para un creyente verdadero. La carta es el cuento. Y al leerla (y leerlo) nos decimos: este sacerdote no miente; todos los datos que enumera son ciertos, pues el catolicismo mexicano es una mezcla sincrética de elementos cristianos y precolombinos. Sin embargo, nos decimos también, este hombre se equivoca y, con ello, damos eco al significado del cuento. Pues sucede que Aub mina las quejas lamentables de su protagonista. Al darle la oportunidad de exagerar la defensa de su caso, Aub nos fuerza a leer a contrapelo de lo expresado por el sacerdote, y terminamos criticándolo: pero es que no comprendiste; llegaste con el propósito de imponer ideas a las personas sin realmente escuchar sus razones.

Justo tal es la intención de Aub: aconsejarnos tener la buena disposición de primero escuchar y luego, de sernos posible, comprender a quienes no piensan como nosotros. Cuando llegamos al cuento llamado "De cómo Julián Calvo quebró por segunda vez", esa idea queda muy clara. Dos exiliados españoles discuten el modo de ser de los obreros mexicanos. Uno de ellos insiste en lo conveniente de prestar atención a esa idiosincracia; el otro cree en actuar obedeciendo a sus propias costumbres extranjeras, que son las correctas y por tanto las únicas aceptables. El título del cuento lo dice todo: quiebra al no conseguir el apoyo de sus empleados.

Así pues, Aub es un narrador que definitivamente cree en darle a cualquier alteridad pie para explicar su condición. Dedica sus cuentos a tal propósito, con resultados excelentes. Representa una actitud contraria a la de Greene. Como dijimos, éste vino a México por un tiempo 
breve, ya con la idea en la mente de que algo estaba muy mal con un país dispuesto en contra de la política eclesiástica. Todo lo que encontró parecía confirmarle su idea. En el caso de Aub, su condición de exiliado político terminó haciéndolo comprender que su estancia aquí era definitiva; por tanto, se dispuso a un acuerdo de convivencia con su nueva realidad.

Desde luego, estam os hablando de actitudes, no de valores literarios. Greene consiguió en The Power and the Glory un drama muy poderoso, $\mathrm{y}$ en tanto que autor es de méritos superiores a los de Max Aub.

Así, hemos llegado al tercer libro. Se titula Las posibilidades del odio, y fue el primero de María Luisa Puga (1944). Los acontecimientos presentados en las distintas tramas ocurren en África. Empecemos, pues, preguntándonos: ¿por qué África? Tenemos la respuesta en De cuerpo entero (1990), la breve autobiografía de la autora. María Luisa divide en ciudades esta exposición de los años que lleva vividos; es decir, según los muchos lugares que fue visitando, pues gustó en el pasado de viajar todo lo posible. Escuchemos sus razones: "Por eso, por mi pareja inacabada, mi novela inacabada. mi visión inacabada del país, me volví a ir. Pensaba que por un año más, pero fueron otros cinco". ${ }^{11}$ Está claro que Puga intentaba encontrarle significado a su vida. Tal vez pertenece a ese grupo de viajeros que Todorov califica de "alegoristas", gente que "habla de un pueblo (extranjero) para debatir sobre alguna cosa distinta a ese pueblo - sobre un problema que concierna al mismo alegorista y a su propia cultura". ${ }^{12}$ Sin duda que eso encontramos en la novela que María Luisa sitúa en África.

Pero, antes, comencemos por citar otra idea interesante tomada de la autobiografía: "el escritor es siempre un fuereño". ${ }^{13}$ Y esa condición de externo impone al novelista la obligación de cruzar fronteras, aunque sólo sean aquellas de lo psicológico, en busca de sus personajes. Este cruce de fronteras - algunas geográficas y otras culturales- da a Las posibilidades del odio un complejo tejido de relaciones y, sin duda, de puntos de vista. En la sucesión de cuentos que compone el libro se incluyen muchas maneras diferentes de comprender el mundo.

En primer lugar, tenemos la visión general perteneciente al autor. $Y$ sí queremos decir el autor: Puga misma, que juega a ser invisible y, sin embargo, todo lo observa mediante los ojos de sus distintos narradores.

$"$ María Luisa Puga, De cuerpo entero. México, UNAM/Eco, 1990, p. 45.

12 T. TODOROV, op. cit., p. 393.

${ }^{13}$ M. L. PUGA, op. cit., p. 55. 
Luego, Puga como personaje del libro. En cuanto tal, pertenece al último y más largo de los capítulos. Y nos tropezamos aquí con un interesantísimo empleo de la perspectiva, pues dicho personaje -a quien la protagonista llama "la mexicana"- viene a nosotros filtrado, precisamente, por los ojos de esa protagonista. Meditemos esto: una escritora mexicana se ve en la visión extranjera de una africana. Un recordatorio urgente: la otredad pertenece a la visitante mexicana, no al personaje que la mira. En otras palabras, Puga se mete al interior de la protagonista africana e intenta entenderse aplicando la vara de medir de una cultura ajena. Una cita nos ayudará a comprender esto. Nyambura, el personaje principal, piensa en esta chica mexicana, a quien conoció en el último día del curso de literatura, y dice: "la mexicana (que quería escribir un libro sobre Nairobi, le había dicho) se había mostrado muy ansiosa porque Nyambura no la fuera a confundir con los blancos (y no era blanca, más bien parecía asiática)". ${ }^{14}$ Sabemos que el libro fue escrito porque, desde luego, lo estamos leyendo. Así que la mexicana cumplió su promesa. Segundo aspecto: incluso la protagonista africana acepta que la visitante se redime por no ser blanca. Resulta patente que Nyambura está observando a la extranjera a partir de los conflictos que a ella la afectan, y que ajusta sus reacciones a la otra chica de acuerdo con esos problemas. Es decir, el texto funciona en dos niveles: entrega algunos datos ciertos respecto a la estudiante mexicana, y entrega algunos datos ciertos respecto a la protagonista. Al mismo tiempo, nos pide ser cautelosos con las opiniones de Nyambura, pues nos llegan teñidas de prejuicios. Como en una ocasión le dice a Nyambura su novio italiano: "pero tú nunca les perdonaste que fueran blancos". ${ }^{15}$

Entonces, una autora mexicana fue a Nairobi, se enfrentó allí a su propia alteridad en ojos de la gente de esa región, y regresó a escribir sobre esa experiencia. Su idea de partida fue muy sencilla: "era la pobreza la que era igual en todas partes". ${ }^{16}$ En el libro de Puga el mundo está dividido en dos mitades: los ricos y los pobres. Para ella, en esa circunstancia tenemos el conflicto central, la otredad de mayor significación en nuestro planeta. Pero estaríamos ante una novela sumamente ingenua si todo se examinara desde esa generalización extrema. Como dijimos, Las posibilidades del odio presenta una compleja red de perspectivas.

\footnotetext{
${ }^{14}$ M. L. PugA, Las posibilidades del odio.2a. ed. México, Siglo XXI, 1980, pp. 271-272.

15 Ibid., p. 296.

${ }^{16}$ Ibid., p. 88.
} 
El primer capítulo plantea la confrontación de un africano blanco con varios ingleses y unos cuantos negros. El ennfrentamiento termina en un desastre para el protagonista: se ve como un blanco y se piensa merecedor de todos los derechos que a tal condición se atribuyen. Mas para los ingleses no pasa de ser otro nativo $y$, por tanto, un ciudadano de segunda categoría. Los negros lo consideran un mero sirviente de los europeos. Al final de todo, el pobre individuo no sabe ya qué condición social asignarse. Puga trabaja con cuidado las diversas perspectivas o enfoques, haciéndonos ver cuán desencontradas pueden ser las imágenes surgidas de una misma situación.

La segunda entrega tiene como sostén una perspectiva negra, ya que un niño y un mendigo se miran desde niveles sociales muy distintos. Puga permite en el niño una preocupación sin duda ingenua, pero a la vez genuina, por esa intrigante persona vista diariamente, cuando asido a la mano de la madre va camino de la escuela. Ese pordiosero es un acertijo que al niño le resulta imposible de resolver: ¿por qué está allí todo el tiempo, sentado y con la mano extendida? El mendigo sólo hace un comentario respecto al escolar: "habia uno negro que pasaba a diario, a la misma hora, de la mano de su madre". ${ }^{17}$ Es aquí, por terminar el capitulo, donde el lector se entera de que el niño también es negro. Puga vino describiendo de tal manera las impresiones del chiquillo, que fácilmente podrían ser las de un blanco. Se prueba así, cabalmente, cómo el trabajo con los puntos de vista afecta nuestra interpretación del texto. $Y$, desde luego, los puntos de vista que el narrador aplica al discurso establecen esa preocupación honda por una naturaleza que simplemente no comprendemos.

El capitulo tres nos informa de la cautelosa amistad entre un viajero mexicano y un keniano, quienes terminan yendo juntos a Nairobi. Aquí, el cambio se da del desconocimiento al conocimiento. Es decir, la alteridad comienza a desaparecer gradualmente, estableciendo una regla respecto a sí misma: en cuanto aceptamos las diferencias que son derecho de los demás, la otredad se transforma en una caracteristica de esas naturalezas que termina siéndonos familiar. Conocer significa no temer.

Ese capitulo tres describe cómo el viajero mexicano y su acompañante keniano eliminan los malentendidos mutuos. Y, punto de mucha mayor importancia, cómo terminan conociendo mejor la naturaleza propia al mejorar su conocimiento de la ajena. Paradoja interesante: el conoci-

${ }^{17}$ Ibid., p. 37. 
miento de sí mismo es en parte interés por la demás gente. Jeremiah, el keniano, afirma de entrada: "los blancos vienen de otro mundo, un mundo desconocido", y termina confesando que gracias a esos blancos ha descubierto muchas cosas nuevas acerca de sí mismo.

Desde luego, en el texto se dan más conflictos que los hasta el momento presentados. Por ejemplo, Jeremiah se siente ajeno a las costumbres de los suazilis y, en tanto que producto del campo, odia los muchos aspectos extraños que encuentra en la capital de Kenia. Y ese conflicto entre la perspectiva cultural del campo y la impersonal existencia de la ciudad aparece, como elemento de indudable importancia, en el núcleo de este libro, para crear otra zona de roces a causa de los malentendidos y desencuentros.

De esta manera, y dado lo visto hasta el momento, no es desacertada la afirmación de que alteridad es aquella naturaleza desconocida que en el otro individuo aguarda nuestro acercamiento. Podemos aproximarnos con la idea de conocerla; podemos examinarla para decirle: pero es que te equivocas en todo, debieras imitarme. Desde luego, al narrador le cabe observar el mundo desde la humilde condición de un personaje menor que, de pronto, hacia el final del texto, se ve desde la perspectiva de quienes lo rodean y descubre cuán insignificante y despreciable lo consideran. Se le plantea entonces el problema de decidir qué hacer o cómo manejar la imagen venida de fuera. ¿Podrá vivir con ese conocimiento nuevo que sobre si mismo tiene? Justo la cuestión que en las páginas finales del cuarto capítulo ha de resolver el protagonista de Puga.

De los libros que hemos venido comentando, el de Puga es el de mayor riqueza desde el punto de vista de nuestro tema, la alteridad. La explicación es por demás sencilla: la autora utiliza muy conscientemente ese recurso para estudiar el problema de las relaciones interculturales. Ahora que toca turno a la novela de Bárbara Jacobs, nos hallamos ante el más ingenuo de los textos abordados, en parte porque Bárbara es todavía una escritora en sus inicios, y en parte debido a las voces narrativas que introduce en el discurso.

Las hojas muertas es el libro que tres hijas escriben en torno a la personalidad de su ya anciano padre. Está dividido en tres partes, una por cada hija. Surge aquí un problema necesario de mencionar: resulta imposible diferenciar las voces de las narradoras, voces que a la vez no cambian con el paso del tiempo. De cualquier manera, Bárbara utiliza el recurso aplicado por Henry James (1843-1916) en What Maisie Knew (1897): permitirnos comprender la vida compleja de los adultos median- 
te la mirada inocente de una chica joven. Ésta no alcanza a captar el significado real de los acontecimientos que narra y, sin embargo, terminamos conociéndolos a fondo gracias a esa visión inocente.

Al comienzo, en el libro de Bárbara tenemos a un hombre ya mayor, quien se aísla de tal manera que crea, alrededor de su existencia, un muro de silencio. Las tres hijas nos van ofreciendo datos acumulativos respecto a ese hombre extraño, con la intención de penetrar en la misteriosa razón de su apartamiento. Desde luego, al final lo consiguen y la información reunida termina explicándonos la vida de ese curioso individuo, el padre. Quien lentamente se transforma de una figura desconocida e incluso atemorizante en un anciano frágil. En las hijas, el temor se vuelve ternura, ternura enraizada en la nueva comprensión de ese acertijo llamado "nuestro padre".

Pero el viaje de conocimiento no ha sido fácil. Distintas barreras dificultaron su cumplimiento. Veámoslas. En primer término, las narradoras. Formadas en el medio cultural capitalino, tienen como primera labor asomarse al ayer de su padre. Y ese ayer transcurrió en dos medios distantes en la geografía y en el tiempo. El inmediato anterior, los años de residencia en Estados Unidos, permiten una asimilación mayor, pues las hijas comparten experiencias en tal país. Aun así, buscan comprender por qué un hostigamiento de orden social va creando en el padre la urgencia del segundo exilio, en México. El lejano lo viven las narradoras en los recuerdos de familia, y es un conjunto de informaciones indirectas, cuya realidad da pie al presente vivido por el padre, aunque sin realmente explicarlo a las hijas.

He aquí pues la situación: el padre constituye el soporte ideológico y sentimental de la novela. Crea, en su relación con las hijas, una otredad que ellas intentan penetrar. La ternura creciente permite que esto se logre en una cierta medida. Ese aislamiento del padre, esa alteridad entercada con que procura dejar al mundo fuera, surge de los tropiezos que el hombre tuvo al enfrentarse con otras culturas, una vez abandonada la propia. Es decir, una asimilación defectuosa en el medio estadounidense, primero, y en el mexicano, después, crea el terco silencio con que, en sus últimos años, el anciano elimina el entorno y crea una geografia interna hecha de lecturas y paseos solitarios. La novela de Bárbara representa el examen de una otredad vista desde los parámetros de nuestra cultura, pues en nuestra cultura se vino a injertar.

Es el momento de volver a una idea expresada por Puga. Pero la abordaremos a partir de un cuentista inglés, V. S. Pritchett (1900), quien dijo en su momento: "a certain foreignness of eye is essential to the good 
short story writer". ${ }^{18}$ Esto parecería oponerse a la famosa afirmación de Flaubert: "Madame Bovary soy yo". Sin embargo, el crítico inglés W. Anderson encuentra en Madame Bovary "a perverse masterpiece, rich in new techniques of impersonal, symbolic narrative". ${ }^{19}$ Entonces, parece existir la posibilidad de intimar con un personaje y, al mismo tiempo, escribir sobre él con un enfoque del todo impersonal. Tal vez en esto se expresa la esencia, o una esencia, de la literatura. Una respuesta posible nos viene de Todorov cuando dice: "aquel que comparte la vida de los chinos hasta el mínimo detalle, olvida que vive con los chinos y, por ende, no los percibe ya como tales". ${ }^{20}$ Se ha convertido en chino sin perder su propio yo cultural.

De esta manera, escribir es cruzar las fronteras psicológicas de nuestros personajes, entrar en su esencia sin mezclarla a la nuestra. Ser los otros y nosotros sin conflictos de personalidad. Por así decirlo, una sana esquizofrenia. Claro, hay muchos caminos para acercarnos a esas alteridades que esperan de nosotros vida en la escritura. Cuando un autor se dedica a gente de su propio país, es mayor la facilidad de la tarea, no importa cuán compleja resulte. Porque si bien encontrará diferencias debidas al sexo, la edad, la condición social, etcétera, todas ellas se dan en una cultura compartida. Pero si es protagonista del texto un extranjero que vive en nuestro país, como ocurre en la obra de Bárbara, tenem os que decidir cuáles reacciones tendrá esa persona ante nuestra idiosincrasia, así como nuestras reacciones, en tanto que escritores, a esas reacciones: ¿procuraremos comprender?, ¿rechazaremos?, ¿habrá posibilidad de un acuerdo? La decisión que tomemos informará del traje ideológico que optemos vestir para la ocasión.

Así con Max Aub. Intenta ver a México desde un punto de vista mexicano, al grado de criticar a ciertos de sus personajes españoles por no comprender al país que los recibe. Una actitud muy liberal desde una perspectiva política. Porque Greene contempla a México preguntándose por qué los mexicanos no pueden ser como los ingleses. El libro de Puga es el mejor ejemplo de lo complejo que puede resultar el acercamiento a los otros. Sin embargo, una actitud notablemente receptiva corre por los distintos capítulos de su libro.

18 Cf. Judith BURnLeY, comp., Penguin Modern Stories, vol. 9. Harmondsworth, Penguin Books, 1971, p. 141.

19 A. K.Thorlby, comp., The Penguin Companion to Literature: European. Harmondsworth, Penguin Books, 1969, p. 272.

${ }^{20}$ T. TODOROV, op. cit., p. 373. 
Para concluir, insistamos en un punto: el modo en que un autor maneje el problema de la otredad nada dice acerca del valor intrínseco de sus obra. Simplemente informa de cómo piensa respecto a esos otros, en ocasiones demasiado ajenos a él porque él los quiere ajenos. 